\title{
Perception and Attitude Changes of Stakeholders for Resilient City Policy by Online Deliberation
}

\author{
Kenshi Baba ${ }^{1 *}$, Eri Amanuma ${ }^{2}$ and Asako Iwami $^{3}$ \\ ${ }^{1}$ Faculty of Environmental Studies, Tokyo City University, Yokohama, Japan, ${ }^{2}$ Center for Climate Change Adaptation, National \\ Institute for Environmental Studies, Tsukuba, Japan, ${ }^{3}$ Faculty of Administrative Studies, Prefectural University of Kumamoto, \\ Kumamoto, Japan
}

\section{OPEN ACCESS}

Edited by:

Ayyoob Sharifi,

Hiroshima University, Japan

Reviewed by:

Prince Dacosta Aboagye, Hiroshima University, Japan Mustapha Raji,

University of Seoul, South Korea

*Correspondence: Kenshi Baba kbaba@tcu.ac.jp

Specialty section: This article was submitted to Smart Technologies and Cities, a section of the journal

Frontiers in Sustainable Cities

Received: 24 August 2021 Accepted: 04 November 2021 Published: 26 November 2021

Citation:

Baba K, Amanuma E and Iwami A (2021) Perception and Attitude Changes of Stakeholders for Resilient City Policy by Online Deliberation. Front. Sustain. Cities 3:763758. doi: 10.3389/frsc.2021.763758
The aim of this study is to clarify the stakeholders' perceptions and attitudes of climate change adaptation in disaster prevention, which is one of the essential factors to make cities resilient, with the expert knowledge and discussion with each other participant via online deliberative experiment. We set up online virtual communities consisting of stakeholders living in disaster-stricken cities and towns who are expected to have a certain stake in this issue, and conducted a deliberation within the communities for 14 days on resilient city policy focusing on climate change adaptation in disaster prevention with the relevant knowledge from experts. We then analyzed changes of the perceptions and attitudes of the participants using the utterances (text data on the message boards) and the questionnaire data of before and after deliberation. The main results are as follows; (i) during the deliberation, a wide range of topics were discussed and converged to policy options over time, (ii) the self-help measures were got understanding of the participants though transformative measures including evacuation for a long time faced negative responses. almost none of the adaptation policies received greater opposition after deliberations than before, participants gained, through discussion, a deeper understanding of measures they themselves could implement (self-help) especially, (iii) perceived effectiveness of adaptation policies have been improved after deliberation, though, cost-benefit evaluation for transformative measures was remarkably lower after deliberation, that is, they will be difficult to implement. Therefore, we need to provide expert knowledge which can make people change their framing.

Keywords: climate change adaptation, disaster prevention, sociopsychology model, questionnaire, text mining

\section{INTRODUCTION}

In Japan, the MLIT (Ministry of Land, Infrastructure, Transport and Tourism of Japan)'s climate change adaptation plan, formulated in November 2015, cited concerns over the various potential impacts of climate change, such as frequent flooding, an increase in the frequency of landslides, an increase in drought damage, changes in water quality, increased risk to communications infrastructure, large-scale temperature increases within the city, impact on business logistics and sightseeing due to storm and flood damage, and more. In addition, the MLIT has cited seven basic approaches to promoting the adaptation policy, such as adaptive management based in uncertainty; comprehensive policies covering both hardware and software; coexistence with nature and harmony with the environment; and promotion of the initiative at multiple stages. Further 
practical adaptation measures were mentioned, such as the stable maintenance of facilities, the operation, maintenance, and updating of equipment, and the design of facilities with minimal reworking for flood control measures; housing construction, tenanting, and land use that take into consideration disaster risk for sediment disaster control measures; and promotion of public awareness and the provision of information (public awareness of climate change, and disaster prevention and mitigation measures; provision of geospatial information) for cross-discipline initiatives (Ministry of Land Infrastructure Transport Tourism of Japan, 2015). These matters are reflected in the National Plan for Climate Change Adaptation, enacted the same month and year by the Cabinet of Japan (Cabinet of Japan, 2015).

As for implementing climate change adaptation policy, integration with mitigation policy, projection of impacts and risk assessments at the local level, communication and collaboration between experts and citizens in vulnerability assessments, and more have been indicated to be necessary so far (for examples, see Kirshen et al., 2008; Halsnæs and Trærup, 2009). In particular, to increase public awareness toward adaptation measures, it is essential to strive to reduce the potential gap in awareness among citizens, policymakers and experts regarding the impact and risks of climate change and gain a greater public understanding of and cooperation with these policies (see Van Aalst et al., 2008).

Given these conditions, it is important to consider to what degree the provision of expert knowledge can change stakeholders' perception and attitude. For example, crosscutting analysis results from Deliberative Polls ${ }^{\circledR}$ conducted across the world indicate that the provision of expert knowledge changes the knowledge of the general public participants (Luskin et al., 2002; Fishkin et al., 2010). There is also an increasing need for policies to be formulated based on scientific evidence, with cocreation frameworks such as co-design and co-production via collaboration between scientists, stakeholders, and the general public (Japan Science Technology Agency, 2012; Future Earth, 2013).

This sort of participatory methods has been applied throughout the world such as consensus conferences, joint fact-finding, and other such initiatives other than Deliberative Polls ${ }^{\circledR}$ (Joss and Durant, 1995; Clinton, 2002). Methods of similar experiments online as a tool to increase opportunities for participation have been steadily conducted. Such online deliberations encourage participants to deepen their understanding of the issues and to think deeply by engaging in discussions with others who have different perspectives. Collins and Nerlich (2015) argued the pros and cons of online discourse, referring to "cyber-optimists" and "cyber-pessimists" and stated that online discourse has the potential for participants to engage in dialog and increase deliberation about the discussed issue, while it discourages alternative viewpoints. In addition, online deliberation fosters participants to take a different stance based on information provided by experts (Talpin and Wojcik, 2010). Deliberation was conducted online to consider the feasibility of concentrated and continuous discussions by a greater number of participants without temporal and geographical restrictions (Janssen and Kies, 2005). Compared to face-to-face discussions, deliberation processes on the Internet have been known to have problems, such as variation in active participation in discussions and dropouts (Wojcieszak, 2011), and to be less likely to result in consensus (Baek et al., 2012). However, it can form a community that is difficult to create in the real world due to time and space constraints, social positions, and interests of the participants, and it can promote deeper thinking and exchange of opinions by learning about the knowledge and opinions of others (Albrecht, 2006; Price et al., 2006; Davies and Gangadharan, 2009; Baba et al., 2015, 2021a; Chen and Zhang, 2020).

Sociopsychological factors that influence individual's perception and behavior need to be considered when attempting to understand the stakeholders' perception and attitude changes. A significant number of behavioral models have been applied to people's perception and behavior toward natural disasters. The examples include TPB (Theory of Planned Behavior) (Lin, 2013; Castillo et al., 2021), Protection Motivation Theory (Bubeck et al., 2018; Babcicky and Seebauer, 2019; Botzen et al., 2019), the Health Belief Model (Ejeta et al., 2016; Tajeri Moghadam et al., 2020), and Construal Level Theory (Deng et al., 2017; Rodríguez-Cruz and Niles, 2021). Ajzen's TPB is a widely used model that proposes the factors of "intention" that motivates "behavior" (Ajzen, 1991). It states that three factors of "attitude toward the behavior," "subjective norm," and "perceived behavioral control" affect "intention." Among three factors that form "intention," only "perceived behavioral control" directly can affect "behavior." In the TPB, the more positive the attitude toward a behavior, the greater the expectation of the behavior from others (subjective norms), and the higher the feasibility of the behavior for oneself (perceived behavioral control), the more the behavior will be carried out. Based on the framework of TPB, Hirose's "Two-phase model for pro-environmental behavior" was developed to examine the process from "behavioral intention" to actual "behavior" with application to environmental issues (Hirose, 1994, 2015). This model is commonly used to investigate people's proenvironmental behaviors (Ohtomo and Hirose, 2007; Kurisu et al., 2019). The causal linkage model assumes that two phases, namely "goal intention" and "behavior intention," are formed before actual environmental conscious behavior. In the first phase, a pro-environmental "goal intention" is formed from the perception of environmental issues (perceived seriousness, ascription of responsibility, and belief in the effectiveness). In the second phase, pro-environmental "behavior intention" is formed from the evaluation of pro-environmental behavior (feasibility evaluation, cost-benefit evaluation, and social-norm evaluation), which connects to actual "behavior." Kurisu et al. (2019) highlighted that Hirose's model follows the assumption from the TPB, and the factor "feasibility" and "social-norm evaluation" in Hirose's model are close to "perceived behavioral control" and "subjective norm" in the TPB, respectively.

Several studies have discussed the perception of disasters caused by climate change. Deng et al. (2017) found that a specific perception of water conservation plays a more critical role than abstract perceptions of climate change in encouraging specific adaptive behaviors in drought-prone southwest China. 
Zaalberg et al. (2009) highlighted that people who have been exposed to flooding in the past perceive them to be more vulnerable to future floods, perceive future flood impacts to be more severe, and have stronger intentions to take adaptation actions than those who have not been exposed in a study conducted in the Netherlands. Boon (2016), on the other hand, investigated the relationship between disaster experience and climate change risk perception and concluded that past disaster experience does not affect climate change risk perception since risk perceptions can be predicted by trust in climate change risk communication, knowledge on climate change, and area of residence. Navarro et al. (2020) studied two disasters in Colombia, coastal flooding and flash floods, and found that in the case of flash floods, a person who has lived in a place longer tend to develop coping strategies to manage stress, whereas, in the case of coastal flooding, risk perception negatively regulates strategies that lead back to emotional regulation and avoidance. The emergence of the internet has provided and diversified opportunities for climate change communication and encouraged discussion among citizens (Papacharissi, 2002; Schäfer, 2012). However, to the best of our knowledge, few studies have investigated the change in people's perception and attitude of adaptation to disasters caused by climate change with the provision of expert knowledge and discussion. Furthermore, there have been few attempts to employ online deliberation and Hirose's pro-environmental framework as described above to examine changes in people's perception.

Therefore, this study aims to clarify the stakeholders' perception and attitude of climate change adaptation in disaster prevention, which is one of the essential factors to make cities resilient, with the expert knowledge and discussion with each other participant via online deliberative experiment.

\section{EXPERIMENT METHOD}

Figure 1 demonstrates the flow of the experiment. First, a simple web survey was conducted over the internet ( $\mathrm{T} 1$; screening survey); residents of disaster-stricken cities and towns, who are considered to have a certain stake in this issue, were first selected by a survey company monitoring on the basis of age (20 years and older) and gender. The disaster-stricken cities and towns cover the entire country from Hokkaido, the northernmost of Japan to Okinawa, the southernmost of Japan. The areas where more than one participates are Tokyo (sixteen), Niigata (eight), Hiroshima (eight) and Aichi (six), and one participant from some other areas. Based on these residents' attributes and their replies regarding the knowledge needed for adaptation policies and their knowledge of global warming, they were sorted into three communities (S, T, U shown in Table 1) of 30 each.

The experiment period consisted of 2 weeks in March 2016. Each community received support via panels of experts assembled by the authors on subjects such as climate change scientist of national research institute and disaster prevention engineer of national university and policymaker of local government, which provided a succession of expert knowledge: moderated debate and discussion then proceeded. Furthermore, the expert knowledge was divided into three topics. The first was "the effects of climate change and natural disasters in Japan," tailored to a degree to match participants' levels of knowledge. The second was "measures for adapting to the effects of climate change and natural disasters." The third was "future adaptation policy options." Discussion proceeded in sets on each topic: expert knowledge was provided, discussion between participants proceeded, and additional explanations were provided by request, with participants being asked to use an online forum as needed for these purposes.

Questionnaire on the website were conducted twice, both before (T2) and after (T3) discussion and provision of information (with more questions prepared for the postdeliberation survey than the pre-deliberation one, four more questions on evaluation of the online deliberation was naturally asked only post-deliberation). In addition, utterances text data was on the message boards. Therefore, each participant had four data sets: his or her survey response data to each of the surveys T1 through T3, and the utterances text data. Ultimately, the number of respondents with all four data sets totaled 61 participants (Table 1). As no significant differences in the average value of responses against questions between groups were observed basically, we present the results as a whole in the following.

The analysis is conducted by building network graphs of words using text data on the message boards, and by structural equation models (SEM) using the questionnaire data to explore the factors affecting stakeholders' perception and attitude toward policies for preventing disasters. SEM integrates methods such as regression analysis, factor analysis, and path analysis, and it is extensively used to examine hypothesized influential factors and paths between various factors (Weston and Gore, 2006). Specifically for this study, we designed the hypothesis and the questionnaire based on Hirose's model (Hirose, 1994, 2015). We explored sociopsychological factors i.e., "realization of climate change impacts," "perceived effectiveness," "norm consciousness," "cost-benefit evaluation," and "feasibility evaluation" as the variables influencing stakeholders' perception and attitude.

\section{ANALYSES USING UTTERANCES (TEXT DATA ON THE MESSAGE BOARDS) AND QUESTIONNAIRE DATA}

\section{Deliberation Overview}

In this section, we shall attempt to understand an overview of the discussion by applying text mining to the utterances of the online deliberative experiment. Specifically, in addition to the three prepared discussions, we extracted the top 30 words by the number of their occurrences in the three communities of $\mathrm{S}, \mathrm{T}$, and $\mathrm{U}$ for a total of five topics set after the "Self-introduction," and before the "Farewell." We then created a network graph using the frequency at which the words occurred in the same utterance ("co-occurrence"). With respect to the target words, the occurrence in one person's utterance is counted as one instance. Since there were multiple words in the 30th place in the number of occurrences in Topic 1, "Climate change and natural disasters in Japan" and "Farewell" at the end, we made 


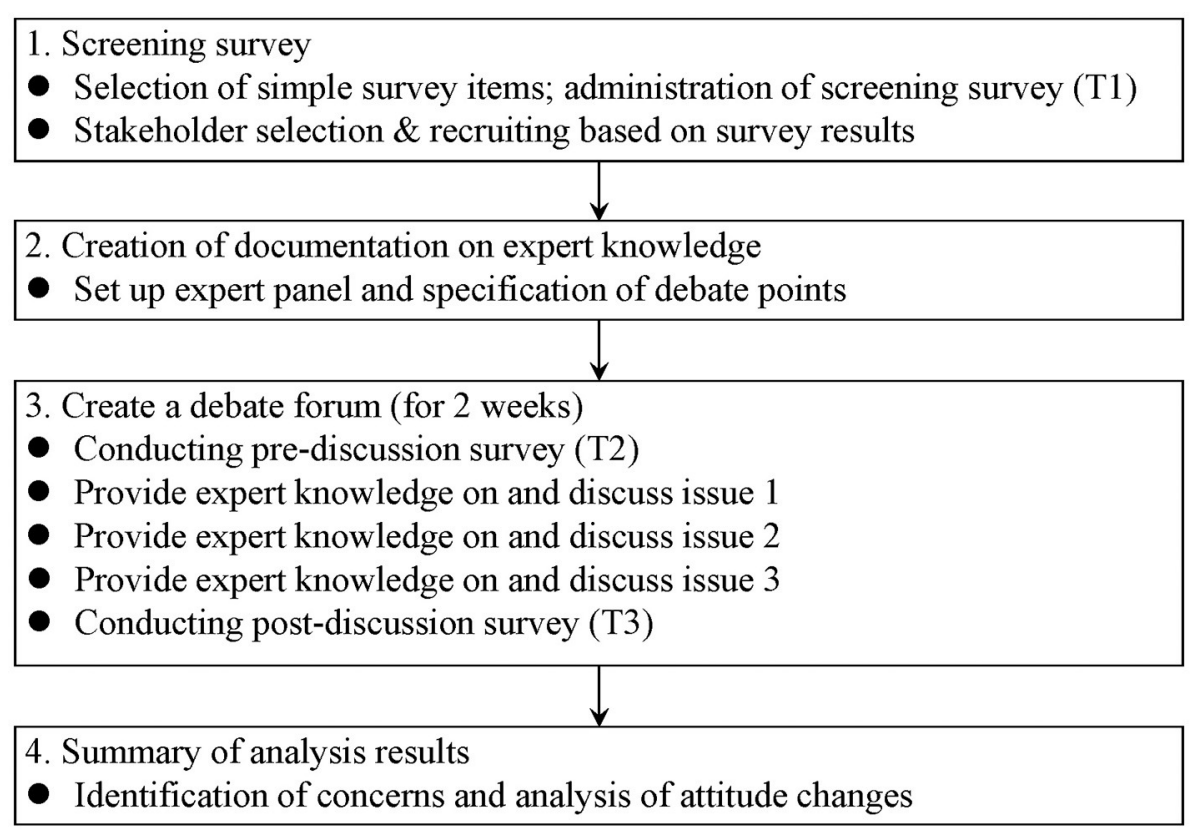

FIGURE 1 | Experiment process of online deliberation.

TABLE 1 | Attributes of community participants.

\begin{tabular}{|c|c|c|c|c|}
\hline & Participants & $\begin{array}{l}\text { Sex ratio } \\
\text { (M/F) }\end{array}$ & Average age & Thoughts on agricultural policies \\
\hline Community S & 19 & $9 / 10$ & 44.8 & \multirow{3}{*}{$\begin{array}{l}\text { No significant difference was observed among } \\
\text { communities in terms of the degree of } \\
\text { agreement for all five questions }\end{array}$} \\
\hline Community $T$ & 24 & $14 / 10$ & 40.9 & \\
\hline Community $U$ & 18 & $11 / 7$ & 44.6 & \\
\hline
\end{tabular}

targets for 32 words and 34 words, respectively. Figure 2 shows the results of the network graph using the extracted target words. In the graph, the size of the nodes (circles) shows the number of occurrences of each word, and the thickness of the edges (lines) connecting one node to another shows the frequency of co-occurrence. In addition, the frequency of co-occurrences was 10 or more in "Self-introduction" and Topics 1-3, while edges were drawn between five or more words in the "Farewell" section. In addition, Table 2 shows the results of calculating the density and concentration, which are indicators of the structure of the network graph. Here, the density is the degree to which the edges that can theoretically exist in the network are actually present, and the concentration is the index reference that indicates the degree to which the edges are concentrated on the nodes that have high centrality (co-occurrence with many nodes) in the graph. In other words, in this study, high density means that target words co-occur with high frequency, high concentration means that words co-occurring with highly central words are concentrated in some utterances, and low concentration means that many words co-occur. As shown in Figure 2, when looking at the size of nodes, the words that frequently appeared in each topic were "please," "climate change," and "theme" in "Self-introduction;" "measures," "materials," and "region" in "Impacts of change and natural disasters in Japan;" "region," "materials," "necessity," and "disaster" in "Future adaptation policy options," - Topic 3; and "participation," "opportunity," and "study" in "Farewell" at the end. The size of nodes varied greatly in "Self-introduction" and "Future adaptation policy options."

Next, focusing on the structure of the network graph of each topic, "Self-introduction" has various words such as "hobby" and "residence" centering on "please." This may be the result of participants freely stating their perceptions and concerns about climate change in their own self-introductions. Similarly, in Topic 1- "Climate change and natural disasters in Japan," there are many words relating to climate change, such as "materials," "causes," and "impacts." We infer that this is because participants discussed the causes and impacts of climate change based on information provided by experts. In addition, Topic 2- "Measures for adapting to the impacts of climate change and natural disasters" includes the words: "region," "self," and "countermeasures." We believe it is likely that there were discussions on disaster prevention countermeasures and initiatives relating to one's self and the region, and on the necessity of such countermeasures in accordance with the topic. 

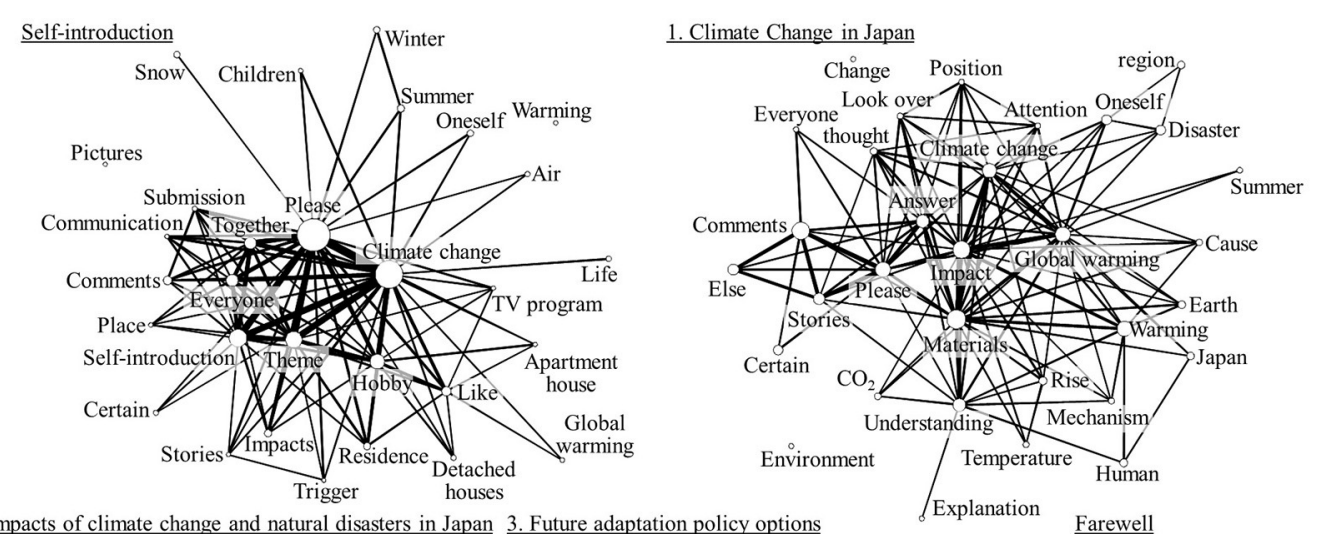

2. The impacts of climate change and natural disasters in Japan 3. Future adaptation policy options Explanation Farewell

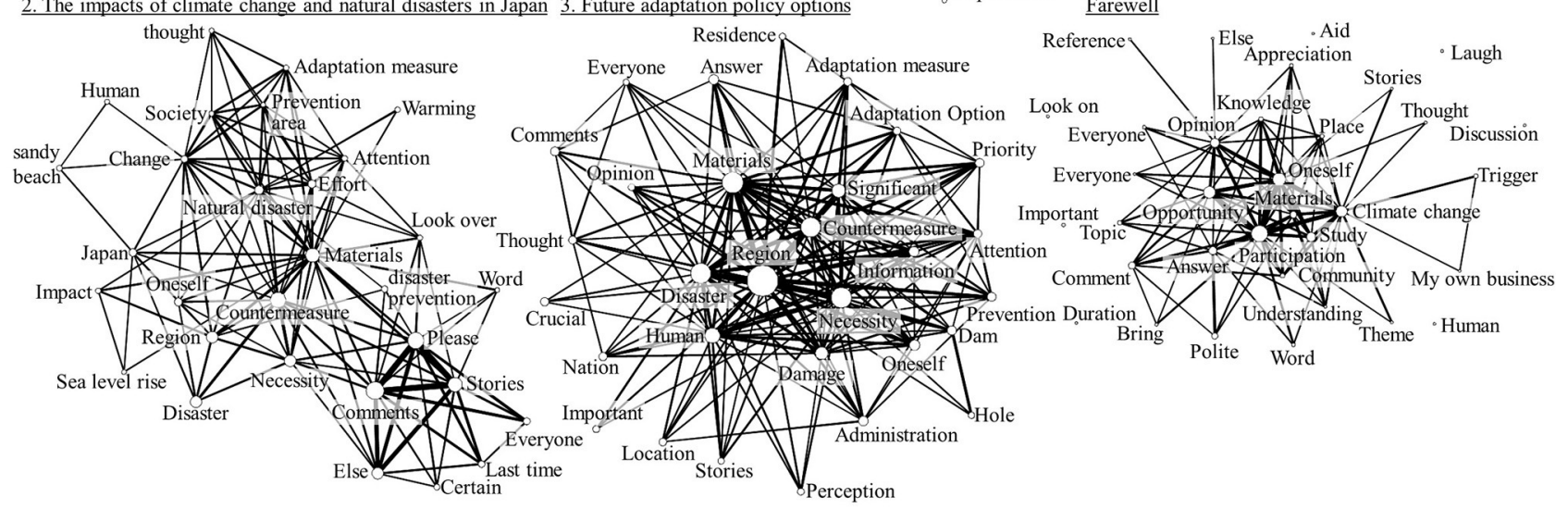

FIGURE 2 | Network Graph of the top word of the number of occurrences in each topic.

TABLE 2 | Density and concentration ratio of the network graph in each topic.

\begin{tabular}{|c|c|c|}
\hline & Density & Concentration ratio \\
\hline Self-introduction & 0.230 & 17.701 \\
\hline 1. The impacts of climate change and natural disasters in Japan & 0.238 & 14.153 \\
\hline 2. Measures for adapting to the impacts of climate change and natural disasters & 0.290 & 13.131 \\
\hline 3. Future adaptation policy options & 0.412 & 16.478 \\
\hline Farewell & 0.039 & 8.442 \\
\hline
\end{tabular}

Topic 3- "Future adaptation policy options," includes words such as "region," "countermeasures," "residence," and "priority." In particular, with respect to "region," it can be seen from the size of the node that the frequency of occurrence is high and many words and edges are connected. From this, we can infer that discussion on regional adaptation policies materialized from the above-mentioned topics. In addition, among the five topics, the number of utterances was the highest in Topic 3 . In "Farewell" at the end, we can see words such as "participation," "materials," and "opinion." It is likely that by participating in online deliberations, this section had many references to information from experts and opinions of other participants.

Focusing on the indicators in the network graph shown in Table 2, Topic 3- "Future adaptation policy options" has the highest density at 0.412 , followed by Topic 2-"Measures for adapting to the impacts of climate change and natural disasters," and Topic 1-"The impacts of climate change and natural disasters in Japan," at 0.290 and 0.238 , respectively. This implies that the highest-ranking words that occur in each topic have the most relevance in Topic 3-"Future adaptation policy options," suggesting that they were concentrated in the scattered discussion in the topic. It also has a higher concentration of 16.478 compared with other topics, supporting the interpretation that it was intensively discussed in the topic. Based on the above, discussions in the online deliberative experiment initially resulted in varied words and varied subjects. However, it can be inferred that the subjects changed in accordance with the topics set and the information provided, they converged and became concrete in Topic 3-"Future adaptation policy options," and a vigorous discussion took place. 


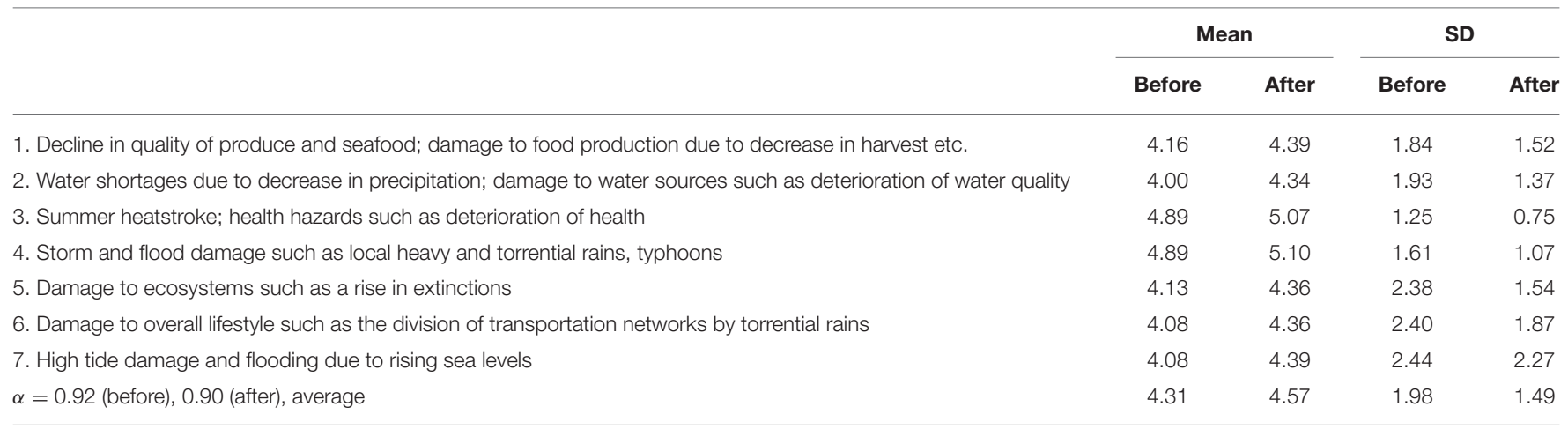

\section{CHANGES IN PERCEPTION AND ATTITUDES BEFORE AND AFTER DELIBERATIONS}

Afterward, data obtained from replies to surveys administered before and after deliberations was studied via comparison to examine how participants' thoughts and attitudes changed.

Table 3 shows the results of questions on realization of the climate change impacts with regard to the possibility of impacts increasing in frequency and magnitude in each area such as crops, water resources, health, storm and flood damage, ecosystems, damage to lifestyles, and sea level rise. Participants were asked to grade these risks on a scale of 1-6 (with 1 indicating no possibility of a new increase in the frequency and magnitude of impacts and 6 indicating an extremely high possibility of a new increase in the frequency and magnitude of impacts); average scores before and after deliberations are shown. On all items, awareness increased, particularly regarding "water shortages and water quality deterioration," where awareness was low before deliberations but made a huge leap subsequently. Also, awareness was highest both before and after deliberations regarding "health hazards" and "storm and flood damage." This shows that many people presume the occurrence of unexpectedly strong rains and typhoons in the statements made during deliberations. Also, all the SD (standard deviation) for each item decreased after deliberation implies that the participants' perception converged with each other. However, no statistically-significant differences were observed for all items though we applied the pared $t$-tests for these items before and after deliberation to verify the changes in attitudes.

Tables 4, 5 show the results of participant polling on whether they agreed with the implementation of 18 measures local governments could take and 19 measures individuals could take as specific precautionary, adaptive, and transformative adaptation policies, scored on a scale of 1 to 6 (with 1 indicating opposition and 6 indicating agreement). The left side shows average scores before deliberations; the right, average scores afterward. Comparison of the average scores before and after deliberation indicates that almost none of the measures received more opposition after deliberations rather than before (meaning, that almost none of the scores went up), and there is a tendency for support for each item to increase in the process of deliberation. In particular, support increased significantly for eight measures local governments could take and 12 measures individuals could take; it could be said that deliberations allowed for a deeper understanding of the measures an individual should take (self-help). This tendency reflects to some extent the abovementioned results of analysis on utterance data in the issue of "climate change adaptation measure options."

Table $\mathbf{6}$ shows the average scores before and after deliberations from respondents on a scale of 1 through 6 (with 1 signifying complete disagreement and 6 signifying complete agreement) evaluating the effectiveness, awareness, and cost-benefit of the various adaptation policies in the major categories of precautionary, adaptive, and transformative measures. For all three categories (precautionary, adaptive, and transformative), scores were higher both before and after deliberations regarding items that claimed implementing these policies would not take much time or labor than they were on other items. Scores for transformative policies were particularly high, and even if the differences were not significant, scores were higher after deliberations than they were before (indicating more negative responses). It could be said that the provision of expert knowledge and the deliberation process led to recognition that these policies cannot be implemented easily.

\section{FACTORS OF ATTITUDE CHANGE}

In Tables 4, 5, we have classified the changes in attitudes for the items for which significant differences were confirmed before and after deliberation into three categories: no change in attitude, changed to support, and changed to opposition. Its relationship with personal attributes (social capital and whether a person has experienced a disaster) is analyzed by testing independence. Tables 7, 8 show some examples of significant differences as a result of the test.

A common observation is that there are many cases in which participants, who have "not experienced a disaster" or have "no association with a local community" changed their attitudes more than other participants. This group had not yet developed an attitude toward measures for adapting to climate change before the deliberations, and these deliberations may have been an 
TABLE 4 | Pros and cons of climate change adaptation policies in disaster prevention (that local governments can take).

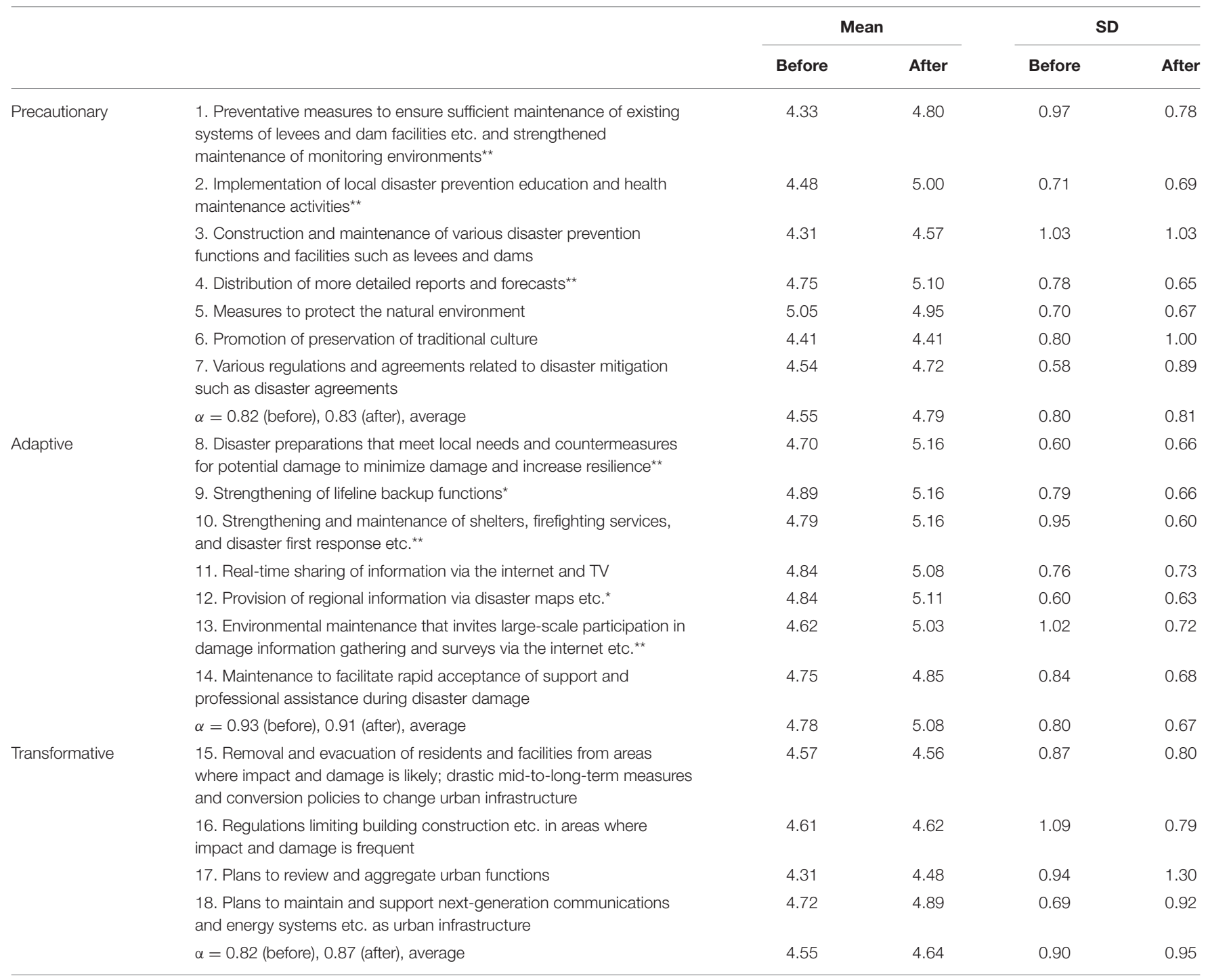

${ }^{* *} 1 \%$ significance; ${ }^{*} 5 \%$ significance.

opportunity for many to deepen their awareness and change their attitudes.

In addition, many of the adaptation policies for which significant differences were confirmed comprised "those that could be taken by local governments," and "those that could be taken only by individuals." This is probably due to the fact that most instances of "disaster prevention efforts" are associated with "local," "taxes," "local government," and "administrative authorities" in the utterance data, suggesting that: vigorous deliberations were held on local government adaptation policies (public help), and participants who had experienced a disaster shared the recognition of the importance of having a relationship with the community based on experience, which imparted new knowledge as well as deepened the thinking of participants who had not experienced a disaster, or who had no relationship with the community.

\section{SOCIOPSYCHOLOGICAL MODEL ANALYSIS}

Based on these results, we conducted a structural analysis of covariance based on the assumptions shown in Figure 3 with respect to factors such as perceived impacts on climate change, as well as perceived effectiveness and evaluation of adaptation policies to comprehensively identify the determinants for the pros and cons of adaptative policies. Since the number of samples was very small $(N=61)$, we constructed models for public help precautionary policies, public help adaptive policies, public assistance conversion policies, self-help precautionary measures, and self-help adaptive measures before and after deliberations, using samples for all the cases (results are not presented for self-assistance conversion measures, in which, Cronbach's alpha does not exceed 0.8 in any way and 
TABLE 5 | Pros and cons of climate change adaptation policies in disaster prevention (that individuals can take).

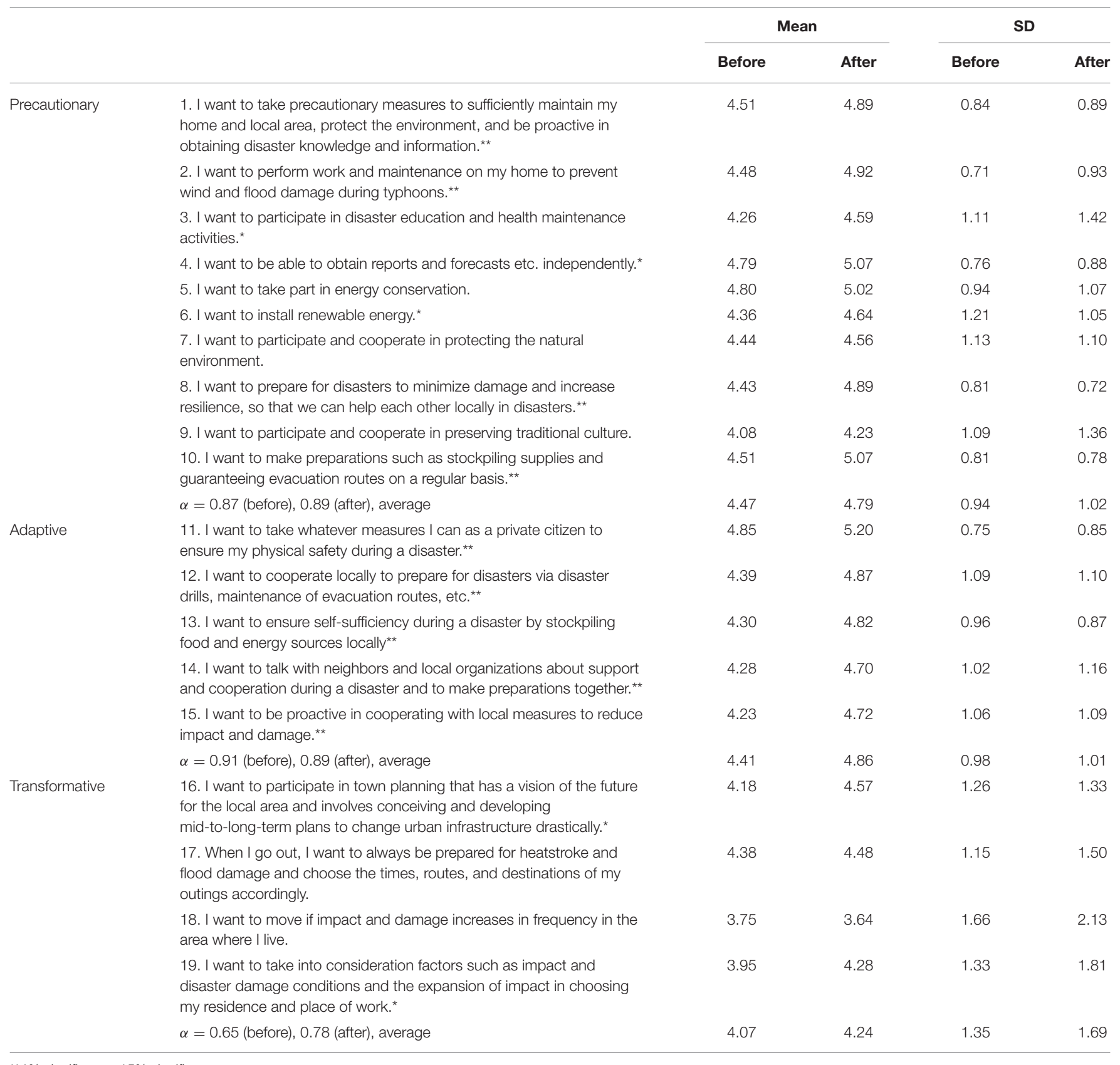

${ }^{\star \star} 1 \%$ significance; ${ }^{\star} 5 \%$ significance.

calculations do not converge). It should be noted that although Table 9 lists the goodness-of-fit and estimated standardized path coefficients, it is extremely difficult to obtain a high goodnessof-fit result for this sample size, and these results are for reference only.

Taking into account such constraints, the following can be noted when reading the large trend of the standardized path coefficients. First, perceived effectiveness affects the pros and cons of climate change adaptive policies in many models; second, climate change perceptions do not independently determine the pros and cons of adaptive policies, but are linked to other sociopsychological factors; and third, other than selfhelp adaptive policies, the determinants change before and after deliberations, and the structure of the determinants change through deliberation.

\section{EVALUATION OF THE ONLINE DELIBERATION}

Finally, in evaluating the online deliberative experiment experience, several points were taken into consideration 
TABLE 6 | Perceived effectiveness, cost-benefit evaluation, feasibility evaluation, and norm consciousness regarding climate change adaptation policies in disaster prevention.

\begin{tabular}{|c|c|c|c|c|c|c|c|}
\hline \multirow{2}{*}{\multicolumn{2}{|c|}{$\begin{array}{l}\text { The upper column: mean } \\
\text { The lower column: SD }\end{array}$}} & \multicolumn{2}{|c|}{ Precautionary } & \multicolumn{2}{|c|}{ Adaptive } & \multicolumn{2}{|c|}{ Transformative } \\
\hline & & Before & After & Before & After & Before & After \\
\hline \multirow{10}{*}{$\begin{array}{l}\text { Perceived } \\
\text { effectiveness }\end{array}$} & \multirow{2}{*}{$\begin{array}{l}\text { 1. They are effective at preventing global warming and disaster } \\
\text { impacts and damage }\end{array}$} & 4.13 & 4.49 & 4.11 & 4.59 & 3.59 & 4.23 \\
\hline & & 1.13 & 1.27 & 1.25 & 1.23 & 1.72 & 1.36 \\
\hline & \multirow{2}{*}{$\begin{array}{l}\text { 2. They are effective in avoiding the intensification of global } \\
\text { warming and disaster impacts and damage }\end{array}$} & 4.23 & 4.66 & 4.3 & 4.74 & 3.66 & 4.34 \\
\hline & & 1.19 & 1.24 & 1.27 & 1.14 & 1.60 & 1.41 \\
\hline & \multirow{2}{*}{$\begin{array}{l}\text { 3. They are effective in preparing for global warming and disaster } \\
\text { impacts and damage }\end{array}$} & 4.18 & 4.66 & 4.34 & 4.72 & 3.9 & 4.48 \\
\hline & & 0.90 & 1.21 & 1.11 & 1.15 & 1.50 & 1.27 \\
\hline & \multirow{2}{*}{$\begin{array}{l}\text { 4. They are effective in reducing global warming and disaster } \\
\text { impacts and damage }\end{array}$} & 4.13 & 4.64 & 4.20 & 4.70 & 3.87 & 4.48 \\
\hline & & 1.03 & 1.28 & 1.27 & 1.03 & 1.46 & 1.40 \\
\hline & \multirow{2}{*}{$\begin{array}{l}\alpha=0.92 \text { (before), } 0.95 \text { (after) for precautionary } \alpha=0.91 \text { (before), } \\
0.95 \text { (after) for adaptive, average } \alpha=0.93 \text { (before), } 0.94 \text { (after) } \\
\text { for transformative }\end{array}$} & 4.17 & 4.61 & 4.21 & 4.69 & 3.75 & 4.38 \\
\hline & & 1.06 & 1.25 & 1.23 & 1.14 & 1.57 & 1.36 \\
\hline \multirow{14}{*}{$\begin{array}{l}\text { Norm } \\
\text { consciousness }\end{array}$} & \multirow[t]{2}{*}{ 5. I feel we should implement these measures } & 4.10 & 4.59 & 4.44 & 4.72 & 3.61 & 3.72 \\
\hline & & 1.07 & 1.36 & 0.84 & 1.03 & 1.68 & 1.51 \\
\hline & \multirow[t]{2}{*}{ 6. I think it is natural that these measures should be implemented } & 4.02 & 4.25 & 4.28 & 4.56 & 3.39 & 3.51 \\
\hline & & 1.10 & 1.63 & 0.99 & 1.49 & 1.91 & 1.5 \\
\hline & \multirow{2}{*}{$\begin{array}{l}\text { 7. Lots of local people are expected to cooperate with these } \\
\text { measures }\end{array}$} & 3.67 & 3.98 & 4.05 & 4.20 & 3.00 & 2.92 \\
\hline & & 1.17 & 1.33 & 0.90 & 1.50 & 1.84 & 2.27 \\
\hline & \multirow{2}{*}{$\begin{array}{l}\text { 8. Lots of people I know are expected to cooperate with these } \\
\text { measures }\end{array}$} & 3.85 & 4.03 & 4.1 & 4.16 & 3.15 & 2.98 \\
\hline & & 1.11 & 1.51 & 0.97 & 1.45 & 1.80 & 1.75 \\
\hline & \multirow[t]{2}{*}{ 9. These measures should be implemented as social norms } & 3.95 & 4.44 & 4.34 & 4.69 & 3.49 & 3.57 \\
\hline & & 1.00 & 1.30 & 0.85 & 1.23 & 1.86 & 1.62 \\
\hline & \multirow[t]{2}{*}{ 10. These measures are socially endorsed } & 4.10 & 4.43 & 4.43 & 4.69 & 3.56 & 3.69 \\
\hline & & 0.94 & 1.13 & 0.83 & 1.03 & 1.72 & 1.46 \\
\hline & $\begin{array}{l}\alpha=0.92 \text { (before), } 0.94 \text { (after) for precautionary } \alpha=0.94 \text { (before), } \\
0.95 \text { (after) for adaptive, average } \alpha=0.96 \text { (before), } 0.94 \text { (after) }\end{array}$ & 3.95 & 4.29 & 4.27 & 4.50 & 3.37 & 3.40 \\
\hline & for transformative & 1.06 & 1.37 & 0.90 & 1.29 & 1.80 & 1.69 \\
\hline \multirow{16}{*}{$\begin{array}{l}\text { Cost-benefit } \\
\text { evaluation }\end{array}$} & \multirow{2}{*}{$\begin{array}{l}\text { 11. Implementing these measures would make our lives more } \\
\text { comfortable }\end{array}$} & 3.69 & 3.98 & 3.97 & 4.16 & 3.3 & 3.61 \\
\hline & & 1.26 & 1.46 & 0.92 & 1.71 & 1.62 & 1.71 \\
\hline & \multirow[t]{2}{*}{ 12. These measures would on the whole lead to financial profit } & 3.56 & 3.97 & 4.00 & 4.26 & 3.59 & 3.69 \\
\hline & & 1.39 & 1.74 & 1.51 & 1.73 & 1.75 & 2.15 \\
\hline & \multirow{2}{*}{$\begin{array}{l}\text { 13. The initial investment for these measures is within a feasible } \\
\text { range }\end{array}$} & 3.20 & 3.46 & 3.64 & 3.85 & 2.80 & 2.56 \\
\hline & & 1.27 & 1.43 & 1.48 & 1.54 & 2.03 & 2.05 \\
\hline & 14. These measures can be implemented right & 2.97 & 2.93 & 3.44 & 3.51 & 2.43 & 2.20 \\
\hline & & 2.00 & 2.16 & 1.69 & 1.69 & 2.11 & 2.13 \\
\hline & 15. These measures can be implemented easily/implementing & 2.80 & 2.90 & 3.38 & 3.38 & 2.39 & 2.15 \\
\hline & them would not require work & 1.83 & 2.51 & 1.68 & 1.78 & 1.88 & 2.22 \\
\hline & 16. These measures would guarantee safety and peace of mind & 4.21 & 4.46 & 4.41 & 4.66 & 3.92 & 4.30 \\
\hline & during a disaster & 0.92 & 1.30 & 0.77 & 1.47 & 1.68 & 1.65 \\
\hline & 17. These measures would revitalize the local area & 3.49 & 3.80 & 3.82 & 4.11 & 3.3 & 3.51 \\
\hline & & 1.59 & 1.96 & 1.75 & 1.81 & 2.18 & 2.15 \\
\hline & $\begin{array}{l}\alpha=0.90 \text { (before), } 0.92 \text { (after) for precautionary } \alpha=0.89 \text { (before), } \\
0.89 \text { (after) for adaptive, average } \alpha=0.92 \text { (before), } 0.89 \text { (after) }\end{array}$ & 3.42 & 3.64 & 3.81 & 3.99 & 3.10 & 3.14 \\
\hline & for transtormative & 1.47 & 1.79 & 1.40 & 1.68 & 1.89 & 2.01 \\
\hline Feasibility & 18. Implementing these measures in our area would be difficult & 3.87 & 3.92 & 3.62 & 3.43 & 4.26 & 4.48 \\
\hline evaluation & from a realistic standpoint & 1.23 & 1.42 & 1.32 & 1.42 & 1.54 & 1.69 \\
\hline & 19. We will not have the opportunity to implement these measures & 3.82 & 3.79 & 3.57 & 3.59 & 4.13 & 4.28 \\
\hline & & 1.16 & 1.02 & 1.36 & 1.26 & 1.43 & 1.45 \\
\hline & $\alpha=0.78$ (before), 0.82 (after) for precautionary $\alpha=0.88$ (before), & 3.84 & 3.85 & 3.59 & 3.51 & 4.20 & 4.38 \\
\hline & $\begin{array}{l}0.81 \text { (after) for adaptive, average } \alpha=0.91 \text { (before), } 0.87 \text { (after) } \\
\text { for transformative }\end{array}$ & 1.20 & 1.22 & 1.34 & 1.34 & 1.48 & 1.57 \\
\hline
\end{tabular}

Dark shaded $=1 \%$ significance; light shaded $=5 \%$ significance. 
TABLE 7 | Changes before and after deliberations regarding the pros and cons of adaptation policies that local governments can implement by social capital (measures to provide facilities such as levees and dams, and to strengthen the development of monitoring environments).

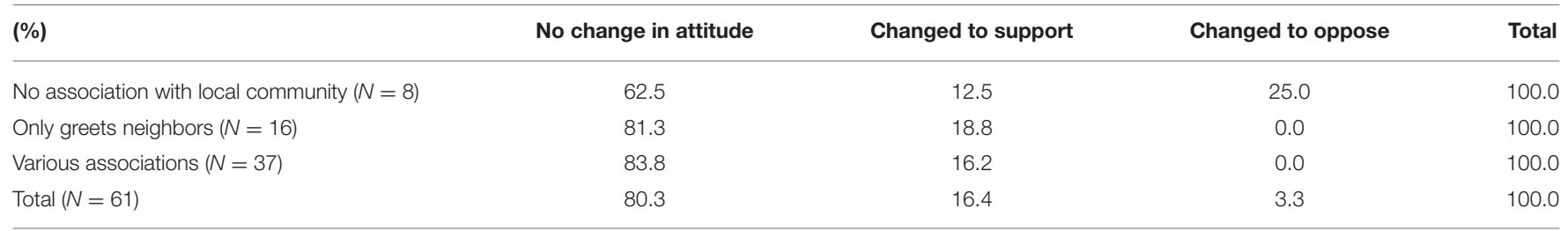

$\chi^{2}=13.752, d f=4, p=0.008$, Fisher's exact test; 0.070 .

TABLE 8 | Changes before and after deliberations regarding the pros and cons of adaptation policies that local governments can take by having experienced a disaster (implementation of disaster prevention education and health maintenance activities in local communities).

\begin{tabular}{lccr}
\hline (\%) & No change in attitude & Transform to affirmative & Transformation to the contrary \\
\hline Has experienced a disaster $(N=41)$ & 92.7 & 7.3 & Total \\
Has not experienced a disaster $(N=20)$ & 80.0 & 5.0 & 100.0 \\
Total $(N=61)$ & 88.5 & 6.6 & 15.0 \\
\hline
\end{tabular}

$\chi^{2}=6.504, d f=2, p=0.039$, Fisher's exact test; 0.041 .

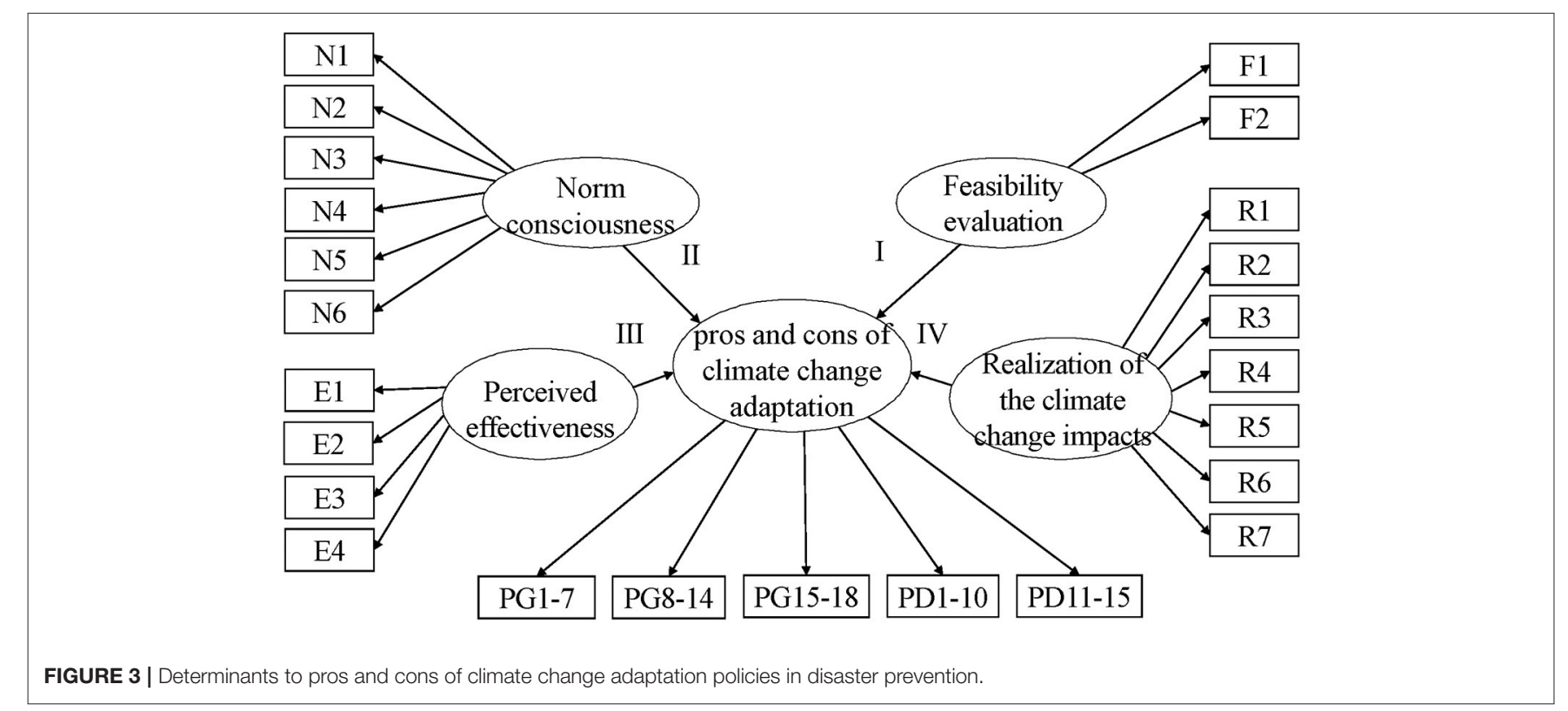

(Table 10). First, when participants were asked to rate the conditions of deliberation on a scale of 1 to 5 (with 1 signifying "do not agree at all" and 5 signifying "very much agree"), the score for the item "discussions centered around several people who spoke frequently" was the highest, followed by the item "lively discussions were held between my fellow participants," indicating a split regarding the state of member participation in the actual discussion.

Next, when participants were asked in a similar manner about the state of their own participation, the score for the item "I was able to learn a great deal about the opinions of other participants in the community" received exceptionally high marks; it was followed, however, by the item "it was difficult to discuss prioritizing options for adaptation in the community."
This is considered to correspond to the high score of "Difficult to understand" in the evaluation of "Provided expert knowledge" asked in the same form. However, the score for "Match with my needs to know" was the next highest, indicating that the expert knowledge provided along with the responses of experts did not deviate from the points that participants wanted to know. It is believed that this also contributed to the provision of additional explanations in response to requests.

\section{DISCUSSION}

First, it can be said that the perceptions relating to "wind and flood damage" as well as "health damage" are high given that 
TABLE 9 | Goodness-of-fit indicators and standardized path coefficients for structural equation models (SEM) analysis results.

\begin{tabular}{|c|c|c|c|c|c|c|c|}
\hline & AGFI & CFI & RMSEA & $\mathbf{I}$ & II & III & IV \\
\hline (i) Public help/precautionary (before) & 0.593 & 0.811 & 0.167 & & & $0.630^{\star \star}$ & \\
\hline (ii) Public help/precautionary (after) & 0.561 & 0.778 & 0.188 & & $0.820^{\star \star}$ & & \\
\hline (iii) Public help/adaptive (before) & 0.656 & 0.898 & 0.101 & & & $0.449^{\star \star}$ & $321^{\star *}$ \\
\hline (iv) Public help/adaptive (after) & 0.634 & 0.857 & 0.119 & & $0.552^{\star \star}$ & & $0.287^{\star *}$ \\
\hline (v) Public help/transformative (before) & 0.663 & 0.910 & 0.103 & & & $0.386^{\star \star}$ & $0.317^{\star *}$ \\
\hline (vi) Public help/transformative (after) & 0.663 & 0.905 & 0.117 & $0.272^{*}$ & $0.373^{\star \star}$ & $0.452^{\star \star}$ & \\
\hline (vii) Self-help/precautionary (before) & 0.635 & 0.882 & 0.106 & & & $0.666^{\star \star}$ & $0.414^{\star \star}$ \\
\hline (viii) Self-help/precautionary (after) & 0.581 & 0.814 & 0.180 & & $0.608^{\star \star}$ & & \\
\hline (ix) Self-help/adaptive (before) & 0.669 & 0.881 & 0.151 & & & $0.700^{\star \star}$ & \\
\hline (x) Self-help/adaptive (after) & 0.687 & 0.907 & 0.140 & & & $0.546^{\star \star}$ & \\
\hline
\end{tabular}

${ }^{\star \star} 1 \%$ significance; ${ }^{\star} 5 \%$ significance.

TABLE 10 | Evaluation of the online deliberation.

\section{Deliberation as a whole}

a. Active discussions took place among participants

b. Discussions moved forward with few individuals, who expressed their views frequently at the core

c. Participants were able to engage in discussions mutually

d. Opinions of every participant were discussed equally

Mean of the evaluation

a. Participants were generally able to state their opinions and thoughts

b. Participants were able to know the opinions of others in the community

c. Other participants listened to my opinions intently

d. My opinions were discussed to a satisfying extent

e. It was difficult to discuss the prioritization of policy options with the community

f. My opinions and thoughts changed through discussions in the community

Mean of the evaluation

SD

\section{Participants collecting information (Multiple answers)}

\subsection{9}

4.26

3.82

3.02

3.97

3.18

0.82

0.62

0.61

0.67

0.98

1.00

Frequency $\%$

1. Did nothing

2. Casually searched on the Internet, etc.

3. Read books thoroughly

4. Discussed with families, friends, and acquaintances

5. Other else

Frequency

Provided expert knowledge

6

47

3

12

5

\begin{tabular}{cc} 
Mean of the evaluation & SD \\
\hline 3.10 & 1.17 \\
3.39 & 1.35 \\
2.90 & 0.94 \\
3.26 & 0.98
\end{tabular}

the perception of climate change impacts-the frequency and possibility of becoming more intense-is almost the same as the results of previous surveys. In Baba et al. (2011) that was conducted nationwide in 2010, the top two responses comprised the perception of "wind and flood damage" and "health damage" -73.4 and 43.8\%, respectively, whereas in Baba and Tanaka (2019) conducted in three agricultural regions in 2014, the perception of "wind and flood damage" was 66.6\% (ranked first) and "health damage" 55.9\% (ranked third). These responses are consistently the top climate change impacts.

In addition, there are few cases in which there has been more opposition to the implementation of precautionary policies, adaptive policies, and conversion policies that can be implemented by local governments and those that can be taken by individuals before and after deliberations, indicating that there is a deeper understanding of policies that should 
be implemented by individuals (self-help) through deliberation. The perceived effectiveness of precautionary, adaptive, and conversion polices has been heightened through deliberation. Conversely, compared with precautionary and adaptive policies, there are generally many negative reactions to conversion policies, and through deliberation, the evaluation of the costs and benefits has been particularly low, and it may be that these policies are recognized as not being easily implementable. Also, perception has a relatively large standard deviation in conversion policies, indicating that there is a large variation in perceptions.

In the context of utterances text data during deliberations, various topics were examined on future adaptation policy options, which supported a certain tendency to deepen the understanding of the policies (self-help) to be taken by individuals. However, the determinants of the pros and cons of adaptive policies changed before and after deliberations, and the structural change of the determinants after deliberation is thought to be one of the results of learning in the context of difficult issues.

Let us look back on the discussion of online vs. face-to-face at the beginning. Online deliberation experiments that share scientific evidence for stakeholders of particular interest and seek to form consensus differ from one-time face-to-face discussions by the general public, such as the deliberative polling, in that, they are conducted online over a relatively long period of time. In addition, attempts to reach a consensus at offline stakeholder meetings in a particular field result in discussions among those with actual interests (e.g. Baba et al., 2021b), whereas online deliberation experiments differ in that they discuss the interests of each real community in a "secure" space, so to speak. Naturally, discussions may differ greatly, in that, face-to-face discussions engage in concurrent oral discussions, while online discussions are sequential text exchanges at the participants' convenience. Online deliberation has several challenges related to the possibility of reinforcing inequalities, creating negative emotions, and the lack of satisfaction derived from not reaching a decision and addressing the issue. Compared to face-to-face deliberations, online deliberations are relatively unstructured and less constrained and do not require consensus and subsequent action (Baek et al., 2012). However, online deliberation can promote a high degree of interaction because it can elicit many responses and ideas posted only once and at any time after the comments (Collins and Nerlich, 2015). It also encourages participants to state diverse opinions based on the information provided by experts (Talpin and Wojcik, 2010), fulfilling central requirements of deliberation: engaging diverse citizens and exposing them to different opinions (Baek et al., 2012). Face-to-face deliberations can strengthen local social capital (Putnam, 2001), while online deliberations, free from geographical constraints, provide more opportunities to interact with politically and racially diverse citizens (Baek et al., 2012).

In this study, the item "participants were able to know the opinions of others in the community" scored the highest in Table 10, which supports the advantage of online deliberation. On the other hand, scores in Table 10 were also high for the items "other participants listened to my opinions intently" and "participants were generally able to state their opinions and thoughts." $75.4 \%$ of participants stated that they looked up information on their own to participate in the online deliberation. Accordingly, as participants conducted their own search before and during online deliberation, they were able to voice their opinions and thoughts, and then interactions were occurred though the issues of the deliberation was considered difficult especially to prioritize adaptation policy options.

\section{CONCLUSION AND FURTHER WORKS}

This study conducted an online deliberative study on the subject of climate change adaptation in disaster prevention, promoted a discussion between participants while sharing expert knowledge, and then clarified changes in participants' knowledge and preferences for adaptation policies. The followings were obtained.

First, we can observe that for the content of deliberation, various words appeared at the beginning, and discussions that expanded the topic to include the causes and impacts of climate change, along with disaster prevention efforts in the participants' regions, according to the set topics and the information provided, intersected and materialized into discussions on regional adaptive policies under Topic 3-"Future adaptation policy options."

Second, when participants were surveyed on whether they agreed with implementation of the specific precautionary, adaptive, and transformative measures which 18 measures local governments could take and 19 measures individuals could take, almost none of the measures received greater opposition after deliberation than before. It could be said that participants gained, through deliberation, a deeper understanding of measures they themselves could implement (self-help) especially.

Third, perceived effectiveness of precautionary, adaptive, and transformative measures have been improved statisticallysignificantly after deliberation. On the other hand, cost-benefit evaluation for transformative measures was remarkably lower after deliberation, that is, transformative measures will be difficult to implement though it was not statistically-significant. Therefore, we need to provide expert knowledge which can make people change their framing.

Fourth, as many participants conducted their own search before and during online deliberation, they were able to voice their opinions and thoughts, and then interactions were occurred though the issues of the deliberation was considered difficult especially to prioritize adaptation policy options.

In the future, more detailed analyses will be conducted on samples whose attitudes have changed, regarding what impact community deliberations had and whether there was a change in the grounds for participants' attitudes, regardless of whether or not those attitudes themselves changed. 


\section{DATA AVAILABILITY STATEMENT}

The raw data supporting the conclusions of this article will be made available by the authors, without undue reservation.

\section{ETHICS STATEMENT}

Ethical review and approval was not required for the study on human participants in accordance with the local legislation and institutional requirements. The patients/participants provided their written informed consent to participate in this study.

\section{AUTHOR CONTRIBUTIONS}

AI conducted text mining, its visualization, and writing. EA conducted mainly SEM analysis, its visualization, and writing. $\mathrm{KB}$ conducted all other works such as conceptualization, experimental design, data collection, basic analysis, writing and

\section{REFERENCES}

Ajzen, I. (1991). The theory of planned behavior. Organ. Behav. Hum. Decis. Process. 50, 179-211. doi: 10.1016/0749-5978(91)90020-T

Albrecht, S. (2006). Whose voice is heard in online deliberation? A study of participation and representation in political debates on the internet. Inf. Commun. Soc. 9, 62-82. doi: 10.1080/13691180500519548

Baba, K., Amanuma, E., and Kosugi, M. (2021a). Attitude changes of stakeholders towards climate change adaptation policies in agricultural sector by online deliberation. Climate 9:75. doi: 10.3390/cli9050075

Baba, K., Doi, M., and Tanaka, M. (2021b). Developing future scenarios for climate change adaptation policy: case study of farming community in Japan. In: Leal Filho W, Luetz J, Ayal D, editors. Handbook of Climate Change Management (Springer: Cham), 1-30. doi: 10.1007/978-3-030-57281-5_280

Baba, K., Kito, M., Takatsu, H., and Matsuura, M. (2015). Stakeholders' attitudes change on wood biomass utilization by online deliberation. J. JSCE 71, 235-246. doi: 10.2208/jscejer.71.I_235

Baba, K., Sugimoto, T., Kubota, H., Hijioka, Y., and Tanaka, M. (2011). Factors to determine risk perception of climate change, and attitude toward adaptation policy of the public. J. JSCE 67, 405-413. doi: 10.2208/jscejer.67.II_405

Baba, K., and Tanaka, M. (2019). Attitudes of farmers and rural area residents toward climate change adaptation measures: their preferences and determinants of their attitudes. Climate 7, 71-81. doi: 10.3390/cli7050071

Babcicky, P., and Seebauer, S. (2019). Unpacking protection motivation theory: evidence for a separate protective and non-protective route in private flood mitigation behavior. J. Risk Res. 22, 1503-1521. doi: 10.1080/13669877.2018.1485175

Baek, Y. M., Wojcieszak, M., and Delli Carpini, M. X. (2012). Online versus face-to-face deliberation: Who? Why? What? With what effects? N. Media Soc. 14, 363-383. doi: 10.1177/14614448114 13191

Boon, H. J. (2016). Perceptions of climate change risk in four disasterimpacted rural Australian towns. Reg. Environ. Change 16, 137-149. doi: 10.1007/s10113-014-0744-3

Botzen, W. J. W., Kunreuther, H., Czajkowski, J., and de Moel, H. (2019). Adoption of individual flood damage mitigation measures in New York City: an extension of protection motivation theory. Risk Anal. 39, 2143-2159. doi: $10.1111 /$ risa. 13318

Bubeck, P., Wouter Botzen, W. J., Laudan, J., Aerts, J. C. J. H., and Thieken, A. H. (2018). Insights into flood-coping appraisals of protection motivation theory: empirical evidence from Germany and France. Risk Anal. 38, 1239-1257. doi: $10.1111 /$ risa. 12938 editing, project administration, funding acquisition, and so on. All authors listed have made a substantial, direct, and intellectual contribution to the work and approved it for publication.

\section{FUNDING}

This study was supported by the Social Implementation Program on Climate Change Adaptation Technology (SI-CAT) of the Ministry of Education, Culture, Sports, Science and Technology (MEXT), Japan, Grant No. JPMXD0715667201 and also supported by the Japan Science and Technology Agency (JST) and the Research Institute of Science and Technology for Society (RISTEX), Japan, Grant No. JPMJRX20B5.

\section{ACKNOWLEDGMENTS}

The authors would like to express our sincere gratitude to the participants and experts, who supported the online deliberation.

Cabinet of Japan (2015). National Plan for Climate Change Adaptation. Available online at: https://www.env.go.jp/earth/tekiou/tekioukeikaku.pdf (accessed: August 23, 2021) (in Japanese).

Castillo, G. M. L., Engler, A., and Wollni, M. (2021). Planned behavior and social capital: understanding farmers' behavior toward pressurized irrigation technologies. Agric. Water Manag. 243:106524. doi: 10.1016/j.agwat.2020.106524

Chen, Z., and Zhang, W. (2020). Bracketing or reinforcing? Socio-economic status, network power, and online deliberation. Telematics Inform. 52:101417. doi: 10.1016/j.tele.2020.101417

Clinton, A. (2002). Humble analysis: the practice of joint fact-finding. Westport, CO.: Praeger.

Collins, L., and Nerlich, B. (2015). Examining user comments for deliberative democracy: a corpus-driven analysis of the climate change debate online. Environ. Commun. 9, 189-207. doi: 10.1080/17524032.2014.981560

Davies, T., and Gangadharan, S. P. (2009). Online Deliberation: Design, Research and Practice. CSLI Publications. Available online at: http://odbook.stanford. edu/static/filedocument/2009/11/10/ODBook.Full.11.3.09.pdf (accessed at: August 23, 2021).

Deng, Y., Wang, M., and Yousefpour, R. (2017). How do people's perceptions and climatic disaster experiences influence their daily behaviors regarding adaptation to climate change? - A case study among young generations. Sci. Total Environ. 581-582:840-847. doi: 10.1016/j.scitotenv.2017.01.022

Ejeta, L. T., Ardalan, A., Paton, D., and Yaseri, M. (2016). Predictors of community preparedness for flood in Dire-Dawa town, Eastern Ethiopia: applying adapted version of health belief model. Int. J. Disaster Risk Reduct. 19, 341-354. doi: 10.1016/j.ijdrr.2016.09.005

Fishkin, J., He, B., Luskin, R., and Siu, A. (2010). Deliberative democracy in an unlikely place: deliberative polling in China. Br. J. Polit. Sci. 40, 435-448. doi: 10.1017/S0007123409990330

Future Earth (2013). Future Earth Initial Design Report. Available online at: https:// edepot.wur.nl/286209 (accessed: August 23, 2021)

Halsnæs, K., and Trærup, S. (2009). Development and climate change: a mainstreaming approach for assessing economic, social, and environmental impacts of adaptation measures. Environ. Manag. 43, 765-778. doi: 10.1007/s00267-009-9273-0

Hirose, Y. (1994). Determinants of environment-conscious behavior. Jpn. J. Soc. Psychol. (in Japanese) 10, 44-55.

Hirose, Y. (2015). Two-Phase Decision-Making Model of Environmental Conscious Behavior and Its Application for The Waste Reduction Behavior, No.5. Safety Science Review. Faculty of Societal Safety Science, Kansai University (2015). p. 81-91. 
Janssen, D., and Kies, R. (2005). Online forums and deliberative democracy. Acta Polit. 40, 317-335. doi: 10.1057/palgrave.ap.5500115

Japan Science and Technology Agency (2012). Strategic Proposal: Toward the Establishment of Principles Regarding the Roles and Responsibilities of Science and Government in Policy Making. Available online at: https://www.jst.go. jp/crds/pdf/2011/SP/CRDS-FY2011-SP-09.pdf (accessed: August 23, 2021) (in Japanese).

Joss, S., and Durant, J. (1995). Public Participation in Science: The Role of Consensus Conferences in Europe. London: Science Museum with the support of the European Commission Directorate General XII.

Kirshen, P., Ruth, M., and Anderson, W. (2008). Interdependencies of urban climate change impacts and adaptation strategies: a case study of Metropolitan Boston USA. Clim. Change 86, 105-122. doi: 10.1007/s10584-0079252-5

Kurisu, K., Kimura, N., and Hanaki, K. (2019). Expression effects of public service advertisements on intentions to act for global warming. J. Clean. Prod. 218, 1045-1054. doi: 10.1016/j.jclepro.2019.02.059

Lin, S. P. (2013). The gap between global issues and personal behaviors: pro-environmental behaviors of citizens toward climate change in Kaohsiung, Taiwan. Mitigation Adaptation Strateg. Glob. Change 18, 773-783. doi: 10.1007/s11027-012-9387-1

Luskin, R., Fishkin, J., and Jowell, R. (2002). Considered opinions: deliberative polling in Britain. Br. J. Polit. Sci. 32, 455-487. doi: $10.1017 /$ S0007123402000194

Ministry of Land Infrastructure Transport and Tourism of Japan The Ministry's Plan for Climate Change Adaptation (2015). Available online at: https://www. mlit.go.jp/common/001264212.pdf (accessed: August 23, 2021) (in Japanese).

Navarro, O., Restrepo-Ochoa, D., Muñoz-Duque, L. A., Zapa-Perez, K., Ameline, A., Mercier, D., et al. (2020). Determinants of coping strategies in two types of natural hazards: flash floods and costal flooding. Int. J. Disaster Risk Reduct. 46:101514. doi: 10.1016/j.ijdrr.2020.101514

Ohtomo, S., and Hirose, Y. (2007). The dual-process of reactive and intentional decision-making involved in eco-friendly behavior. J. Environ. Psychol. 27, 117-125. doi: 10.1016/j.jenvp.2007.01.005

Papacharissi, Z. (2002). The virtual sphere. In: The Information Society Reader. Routledge, pp. 379-92. doi: 10.4324/9780203622278-36

Price, V., Nir, L., and Cappella, J. N. (2006). Normative and informational influences in online political discussions. Commun. Theory 16, 47-74. doi: 10.1111/j.1468-2885.2006. 00005.x

Putnam, R. D. (2001). Bowling Alone: The Collapse and Revival of American Community. New York, NY: Simon and Schuster. 11, 11. doi: $10.1145 / 358916.361990$
Rodríguez-Cruz, L. A., and Niles, M. T. (2021). Awareness of climate change's impacts and motivation to adapt are not enough to drive action: a look of Puerto Rican farmers after Hurricane Maria. PLoS ONE 16:e0244512. doi: 10.1371/journal.pone.0244512

Schäfer, M. S. (2012). Online communication on climate change and climate politics: A literature review. Wiley Interdisciplinary Reviews: Climate Change. Wiley-Blackwell. doi: 10.1002/wcc.191

Tajeri Moghadam, M., Raheli, H., Zarifian, S., and Yazdanpanah, M. (2020). The power of the health belief model (HBM) to predict water demand management: a case study of farmers' water conservation in Iran. J. Environ. Manage. 263:110388. doi: 10.1016/j.jenvman.2020.110388

Talpin, J., and Wojcik, S. (2010). Deliberating environmental policy issues: comparing the learning potential of online and face-to-face discussions on climate change. Policy Internet 2, 61-93. doi: 10.2202/1944-2866.1026

Van Aalst, M. K., Cannon, T., and Burton, I. (2008). Community level adaptation to climate change: the potential role of participatory community risk assessment. Glob. Environ. Change 18, 165-179. doi: 10.1016/j.gloenvcha.2007.06.002

Weston, R., and Gore, P. A. (2006). A brief guide to structural equation modeling. Couns. Psychol. 34, 719-751. doi: 10.1177/0011000006286345

Wojcieszak, M. (2011). Deliberation and attitude polarization. J. Commun. 61, 596-617. doi: 10.1111/j.1460-2466.2011.01568.x

Zaalberg, R., Midden, C., Meijnders, A., and McCalley, T. (2009). Prevention, adaptation, and threat denial: flooding experiences in the Netherlands. Risk Anal. 29, 1759-1778. doi: 10.1111/j.1539-6924.2009.01316.x

Conflict of Interest: The authors declare that the research was conducted in the absence of any commercial or financial relationships that could be construed as a potential conflict of interest.

Publisher's Note: All claims expressed in this article are solely those of the authors and do not necessarily represent those of their affiliated organizations, or those of the publisher, the editors and the reviewers. Any product that may be evaluated in this article, or claim that may be made by its manufacturer, is not guaranteed or endorsed by the publisher.

Copyright (C) 2021 Baba, Amanuma and Iwami. This is an open-access article distributed under the terms of the Creative Commons Attribution License (CC BY). The use, distribution or reproduction in other forums is permitted, provided the original author(s) and the copyright owner(s) are credited and that the original publication in this journal is cited, in accordance with accepted academic practice. No use, distribution or reproduction is permitted which does not comply with these terms. 